\title{
Differentially Interconnected Networks of GABAergic Interneurons in the Visual Cortex of the Cat
}

\author{
Gábor Tamás, ${ }^{1,2}$ Peter Somogyi, ${ }^{1}$ and Eberhard H. Buhl ${ }^{1}$ \\ ${ }_{1}^{1}$ Medical Research Council, Anatomical Neuropharmacology Unit, Department of Pharmacology, University of Oxford, \\ Oxford, OX1 3TH, United Kingdom, and 2Department of Comparative Physiology, József Attila University, Szeged, \\ H-6726, Hungary
}

Networks of GABAergic neurons have been implicated in neuronal population synchronization. To define the extent of cellular interconnections, we determined the effect, number, and subcellular distribution of synapses between putative GABAergic neurons in layers II-IV of the cat visual cortex using paired intracellular recordings in vitro followed by correlated light and electron microscopy. All neurons having interneuronal electrophysiological properties were classified by their postsynaptic target profile and were identified as basket (BC; $n=6)$, dendrite-targeting (DTC; $n=1$ ), and double bouquet (DBC; $n=$ 2) cells. In four out of five anatomically fully recovered and reconstructed cell pairs, synaptic connections were found to be reciprocal. Generally BCs established synaptic junctions closer $(21 \pm 20 \mu \mathrm{m})$ to postsynaptic somata than did DBCs (43 \pm 19 $\mu \mathrm{m} ; p<0.01$ ). The unitary number of synapses ( $n$ values, 10,7 , and 20) in each of three BC-to-BC pairs was higher than that in

Local-circuit GABAergic neurons modulate the operation of excitatory neurons in cortical networks. They govern the generation and backpropagation of action potentials (Andersen et al., 1963; Miles and Wong, 1987; Buhl et al., 1995; Buzsaki et al., 1996; Tsubokawa and Ross, 1996) dendritic calcium electrogenesis (Traub et al., 1994; Miles et al., 1996) and play a role in synchronizing population activity (Cobb et al., 1995; Whittington et al., 1995; Bush and Sejnowski, 1996; Freund and Buzsaki, 1996). Analysis of inhibitory unitary interactions between identified interneurons and principal cells revealed that distinct classes of GABAergic neurons terminate on different subcellular domains and elicit fast IPSPs (Buhl et al., 1994; Miles et al., 1996; Thomson et al., 1996; Tamas et al., 1997a).

Cortical interneurons themselves are also under GABAergic control, because they receive GABAergic afferents from both subcortical and cortical sources. In the neocortex, the main extrinsic source of inhibitory innervation is the basal forebrain, and this pathway terminates predominantly on GABAergic neurons (Freund and Meskenaite, 1992). Cortical GABAergic afferents

Received Dec. 16, 1997; revised March 12, 1998; accepted March 18, 1998.

This project was supported by European Community Grant BIO4-CT96-0585. G.T. was supported by the Oxford-Szeged Scholarship of the Department of Pharmacology, the European Blaschko Visiting Research Scholarship, and the Z. Magyary Scholarship. E.H.B. also holds a Medical Research Fellowship at Corpus Christi College, Oxford. We thank Drs. O. Paulsen and Z. Nusser for critical comments on an earlier version of this manuscript and P. Jays, F. Kennedy, and J. D. B. Roberts for technical and photographic assistance.

Correspondence may be addressed to any of the authors. Reprint requests should be addressed to Dr. Gábor Tamás, Medical Research Council, Anatomical Neuropharmacology Unit, University of Oxford, Mansfield Road, Oxford, OX1 3TH, UK. Copyright (C) 1998 Society for Neuroscience $0270-6474 / 98 / 184255-16 \$ 05.00 / 0$ three BC-to-DBC ( $n$ values, 1, 2, and 2 ) and three DBC-to-BC ( $n$ values, 1,4 , and 4 ) connections $(p<0.05)$. A BC innervated a DTC through two synaptic junctions. Unitary postsynaptic effects mediated by five BCs could be recorded in two BCs, two DBCs, and a DTC. The BCs elicited short-duration fast IPSPs, similar to those mediated by $\mathrm{GABA}_{\mathrm{A}}$ receptors. At a membrane potential of $-55.0 \pm 6.4 \mathrm{mV}$, unitary IPSPs $(n=5)$ had a mean amplitude of $919 \pm 863 \mu \mathrm{V}$. Postsynaptic response failures were absent when an IPSP was mediated by several release sites. Thus, distinct GABAergic interneurons form reciprocally interconnected networks. The strength of innervation and the proximal placement of synapses suggest a prominent role for BCs in governing the activity of intracortical GABAergic networks in layers II-IV.

Key words: cerebral cortex; interneuron; inhibition; IPSP; GABA; synapse

arise either from smooth dendritic interneurons exclusively innervating other GABAergic cells, as recently demonstrated in the hippocampus (Acsady et al., 1996; Gulyas et al., 1996), or from GABAergic neurons divergently innervating both principal and GABAergic neurons (Somogyi et al., 1983; Kisvarday et al., 1985, 1993; Freund et al., 1986; Cobb et al., 1997; Meskenaite, 1997). Moreover, in cat visual cortex, large GABAergic basket cells form an interconnected network linking columns with different orientation preferences (Kisvarday et al., 1993, 1994).

Regarding the functional effect of GABAergic interneurons, the same presynaptic GABAergic cell evoked qualitatively similar fast IPSPs in both postsynaptic interneurons and pyramidal cells (Cobb et al., 1997). Modeling studies indicate that such fast IPSPs can synchronize a network of mutually connected interneurons that, in turn, generates a coherent oscillatory output to principal neurons (Traub et al., 1996; Wang and Buzsaki, 1996). Indeed, recent in vitro experiments show that cortical inhibitory neurons can generate oscillatory network activity in the gamma frequency range (Whittington et al., 1995). Such oscillations occur in the neocortex of behaving animals in response to visual stimulation, and they may be of major importance in the cortical representation of objects, the so-called binding phenomenon [for review, see Singer and Gray (1995)]. Computational simulations of gamma frequency network oscillations require an appreciable degree of mutual connectivity between interneurons and a critical minimum of synaptic connectedness to induce and maintain rhythmic population activity (Traub et al., 1996; Wang and Buzsaki, 1996), but there is little experimental information on the degree of GABAergic interconnections. 

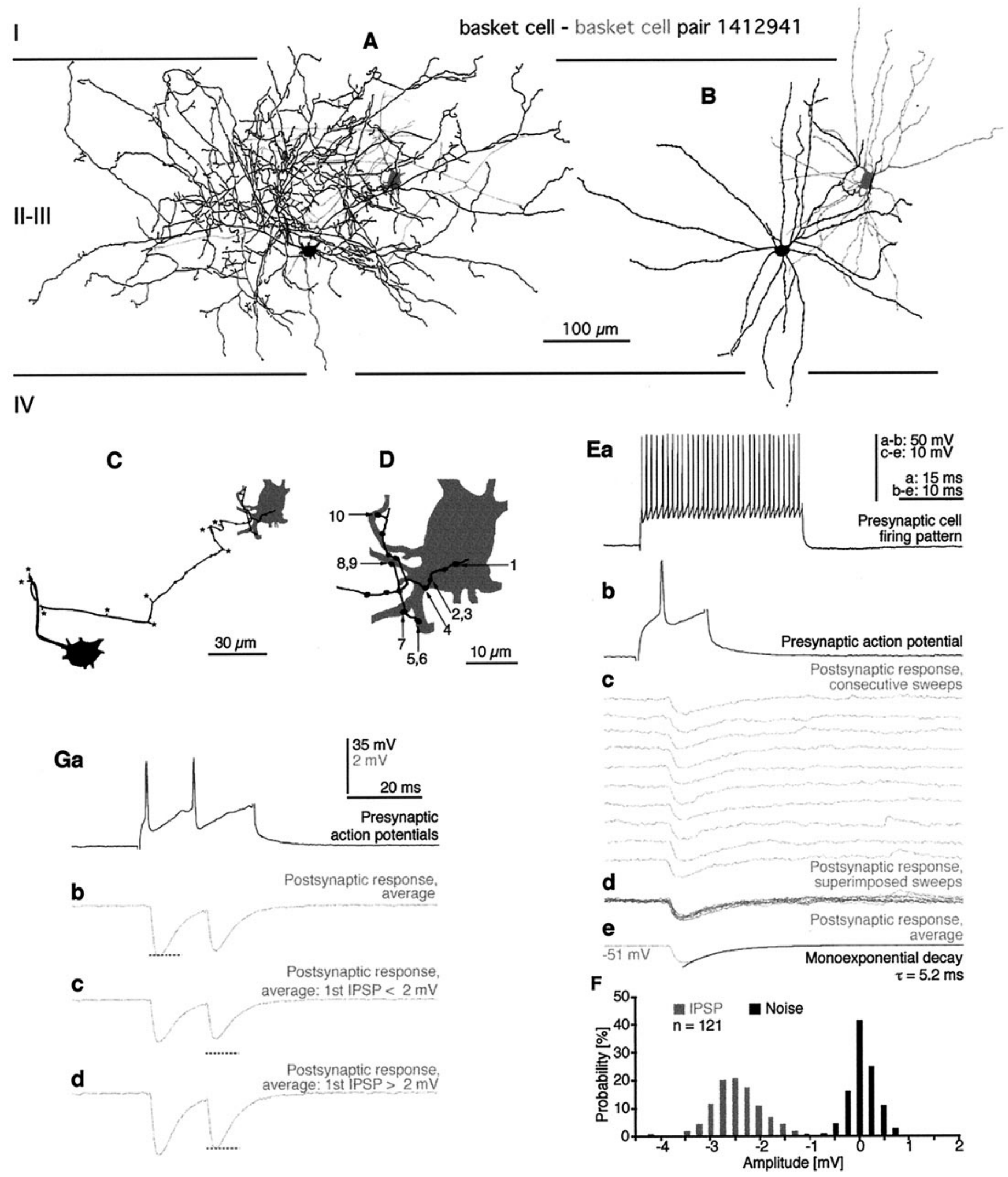

Figure 1. Reconstruction and synaptic effect of a BC-to-BC pair in layers II-III of area 18. $A, B$, Axonal $(A)$ and dendritic $(B)$ arborization of the presynaptic (black) and the postsynaptic (gray) BCs is shown. The axon of the postsynaptic cell was only partially recovered. $C$, The route of the presynaptic axon (black) to synaptic boutons on the postsynaptic cell (gray) is shown. Branch points are indicated by asterisks. D, The locations of electron microscopically verified synaptic junctions between the two BCs are indicated. Four synapses were found on the soma, and six synapses were on proximal dendrites. Three boutons established two distinct synaptic release sites each (grouped numbers). Ea, In response to (Figure legend continues). 
This study addresses the extent and mode of synaptic interactions between GABAergic neurons innervating both spiny and smooth dendritic cells by using in vitro paired intracellular recordings and light and electron microscopy. Below, we not only determine the degree of reciprocity between interneurons, but we also investigate their domain-specific efferent connectivity and specific differences in the strength of unitary connections.

Parts of this paper have been published previously (Tamas et al., 1995, 1997a).

\section{MATERIALS AND METHODS}

Slice preparation. Adult female cats weighing $2.6-3.2 \mathrm{~kg}$ were deeply anesthetized with an intramuscular injection of a mixture of ketamine $(30 \mathrm{mg} / \mathrm{kg})$ and xylazine $(10 \mathrm{mg} / \mathrm{kg})$. After the cessation of noxious reflexes (pedal withdrawal and/or tail pinch reflex), a craniotomy was performed over the occipital cortex, leaving the dura intact. After ensuring adequate levels of anesthesia by ascertaining the loss of pain reflexes (see above), we perfused the animals with $\sim 1.51$ of modified (see below) artificial CSF (ACSF) that had been chilled and oxygenated. Then the dura was opened, and a $5-8 \mathrm{~mm}$ block of occipital cortex was excised from one of the hemispheres and immersed in chilled ACSF. The tissue was sectioned on a vibroslice (Campden Instruments, Loughborough, UK) in the frontal plane at $400 \mu \mathrm{m}$ thickness. The slices were trimmed, keeping primarily the crest of the lateral gyrus, including portions of areas 17 and 18, and then transferred to a recording chamber, where they were maintained at $34-35^{\circ} \mathrm{C}$ on a nylon mesh at the interface between oxygenated ACSF and a humidified atmosphere saturated with $95 \% \mathrm{O}_{2} / 5 \% \mathrm{CO}_{2}$. The normal ACSF was composed of (in $\mathrm{mM}$ ): 126 $\mathrm{NaCl}, 3.0 \mathrm{KCl}, 1.25 \mathrm{NaH}_{2} \mathrm{PO}_{4}, 24 \mathrm{NaHCO}_{3}, 2.0 \mathrm{MgSO}_{4}, 2.0 \mathrm{CaCl}_{2}$, and 10 glucose. During perfusion, cutting, and preincubation, all $\mathrm{NaCl}$ was replaced with equiosmolar sucrose $(252 \mathrm{~mm})$. The slices remained in the sucrose solution for $30 \mathrm{~min}$ before the perfusion medium was changed to normal ACSF.

Intracellular recordings and data analysis. Recording electrodes were pulled from standard wall borosilicate tubing, filled with $2 \%$ biocytin in $1.5 \mathrm{M}$ potassium methyl sulfate, and beveled to a DC resistance of $80-150$ $\mathrm{M} \Omega$. Putative GABAergic neurons were identified by their physiological characteristics, such as short-duration action potentials (APs) followed by large-amplitude fast afterhyperpolarizing potentials (fAHPs) (see Figs. 1Ea, 2Ga) (McCormick et al., 1985). After a stable recording had been obtained, a search was made for cells displaying similar electrophysiological properties (e.g., see Fig. 2J). Capacitive coupling was eliminated on-line using a modified (Mason et al., 1991) Axoprobe amplifier that was operated in bridge mode (Axon Instruments, Foster City, CA). Synaptic coupling was tested using on-line spike-triggered averaging while eliciting firing in the interneuron with depolarizing current pulses. Firing rates in the interneurons were adjusted by varying the current intensity and, depending on the particular protocol, ranged between 0.3 and $>100 \mathrm{~Hz}$. Experimental data were acquired using a pulse code modulation (PCM) instrumentation recorder and were stored on videotapes. Data analysis was continued off-line by (re)digitizing the data at $5-20 \mathrm{kHz}$ using commercially available 12 bit analog-to-digital boards (RC Electronics, Santa Barbara, CA, and National Instruments Labmaster, Newbury, UK) in conjunction with Axograph (Axon Instruments), RC Electronics Computerscope (RC Electronics), and whole-cell program (courtesy of Dr. J. Dempster, University of Strathclyde, UK) software packages.

Resting membrane potentials were determined after electrode withdrawal and are given as the difference between surface DC potential and the most negative steady state membrane potential without bias current injection. Membrane time constants were obtained from the decay of small-amplitude hyperpolarizing current pulses and could be well fitted with a single exponential function in all cells. Likewise, input resistance was determined from measuring the maximal deflection of averaged small-amplitude hyperpolarizing current pulses. Spike amplitudes were taken from baseline to the peak of the action potential; spike duration was measured at half-amplitude. Unitary IPSP amplitudes were measured from baseline to peak. The corresponding noise levels were determined for the same time interval from baseline to baseline, using the pre-event interval of the same traces. Distributions of measured IPSP and noise amplitudes showed no significant differences relative to ideal normal distributions (Kolmogorov-Smirnov normality tests; $p>0.516$ ). Data for amplitude histograms were used only from epochs in which the postsynaptic responses remained stationary, defined as epochs during which (1) the mean amplitude of 50 consecutive IPSPs remained within $\pm 1 \mathrm{SD}$ of the mean amplitude of the first 50 IPSPs of the epoch and (2) no significant change of either IPSP or noise amplitudes was noted over time (Pearson correlation; $p>0.08$ ).

To assess paired-pulse modulation of unitary IPSPs, we elicited consecutive action potentials in the presynaptic cells $(n=2)$ by injecting either a single current pulse of $100-200 \mathrm{msec}$ duration evoking two action potentials or two brief consecutive current pulses with one action potential each. Both cells were activated at a rate of $1 \mathrm{~Hz}$. All synaptic events (see Figs. 1, 2, in which $n$ is 25 or 217 in cell pairs, respectively) were aligned on the rising phase of the first presynaptic action potential and subsequently, because of variations of the interspike intervals, realigned on the rising phase of the successive second action potential. Then, the respective voltage traces of the postsynaptic cell were averaged over each of four equal-length periods, with those used for noise and IPSP measurements separated by equal intervals. Average voltages for the first two periods preceding the synaptic event were calculated for each sweep, and their respective differences provided the noise sample distribution. Likewise, IPSP peak amplitude measurements were obtained from the set of differences between the average voltage of a period preceding the IPSP and the time window encompassing the peak of the IPSP. Because of some relatively brief interspike intervals $(<70 \mathrm{msec})$ that were used to evoke paired-pulse modulation of unitary IPSPs, the ongoing decay of the first, conditioning IPSPs could significantly overlap with the rise of the successive event, essentially arising from a sloping baseline and therefore affecting the measurements of the second IPSP. Assuming linear summation of the recorded voltage, we corrected the amplitude measurements that were obtained for the second IPSP (all events $\geq 2 \times \mathrm{SD}$ of noise) for the extrapolated decay of the preceding IPSP, taking into account the respective interspike interval as well as the peak amplitude and monoexponential decay kinetics of the conditioning event.

Histological processing and anatomical evaluation. In most of the cases, diff usion, presumably aided by current pulses (0.1-0.5 nA) used during recording, resulted in an adequate filling of neurons with biocytin. Slices were sandwiched between two Millipore filters to avoid deformations and were fixed in $2.5 \%$ paraformaldehyde, $1.25 \%$ glutaraldehyde, and $15 \%$ $(\mathrm{v} / \mathrm{v})$ saturated picric acid in $0.1 \mathrm{~m}$ phosphate buffer, $\mathrm{pH} 7.4$, for 12-24 hr. The tissue processing was based on previously described procedures (Han et al., 1993; Buhl et al., 1994). Briefly, after gelatin embedding, the slices were resectioned at $60 \mu \mathrm{m}$ thickness, and the biocytin-filled cells were visualized by the avidin-biotinylated horseradish peroxidase method with diaminobenzidine as the chromogen. Sections were postfixed with $1 \% \mathrm{OsO}_{4}$, block-stained in $1 \%$ uranyl acetate, dehydrated, and embedded into epoxy resin (Durcupan; Fluka, Buchs, Switzerland) on glass slides.

Recovered cells were reconstructed at $1250 \times$ magnification from the serial, $60-\mu \mathrm{m}$-thick sections of the entire slice using a light microscope and a drawing tube. Although cells can be filled completely, the reagents used for visualizing biocytin do not penetrate well into the myelinated segments of axons, which often remain faint. Nevertheless, the axons can be followed accurately along the Ranvier nodes that are stained and easily recognized in osmium-treated material. The total number of axonal varicosities in the slice, some of them shown by subsequent

depolarizing current pulses of $0.5 \mathrm{nA}$, the presynaptic BC fired nonaccommodating trains of APs followed by a deep, fast AHP. Eb, Ee, Action potentials $(\sim 1 \mathrm{~Hz})$ of the presynaptic cell resulted in a short-latency, fast IPSP (amplitude in $E e,-2.40 \pm 0.48 \mathrm{mV}$ ) in the postsynaptic BC depolarized to a membrane potential of $-51 \mathrm{mV}$. $E c, E d$, Ten consecutive sweeps illustrate the small variability of unitary IPSPs. In $E a$ and $E b$, capacitance artifacts are truncated for clarity. $F$, The segregation of IPSP and noise amplitude distributions demonstrates the absence of response failures. $G$, By adjusting the pulse duration and current intensity to elicit two APs $(G a)$, modest paired-pulse (PP) depression of the second IPSP became apparent after averaging $(G b)$. $G c, G d$, When compared with the mean amplitude of all conditioning first IPSPs $(G b$; indicated by the dotted line), PP depression was apparent after IPSP1s smaller than $-2 \mathrm{mV}$ in amplitude $(G c)$ but not after IPSP1s larger than $-2 \mathrm{mV}(G d)$. 

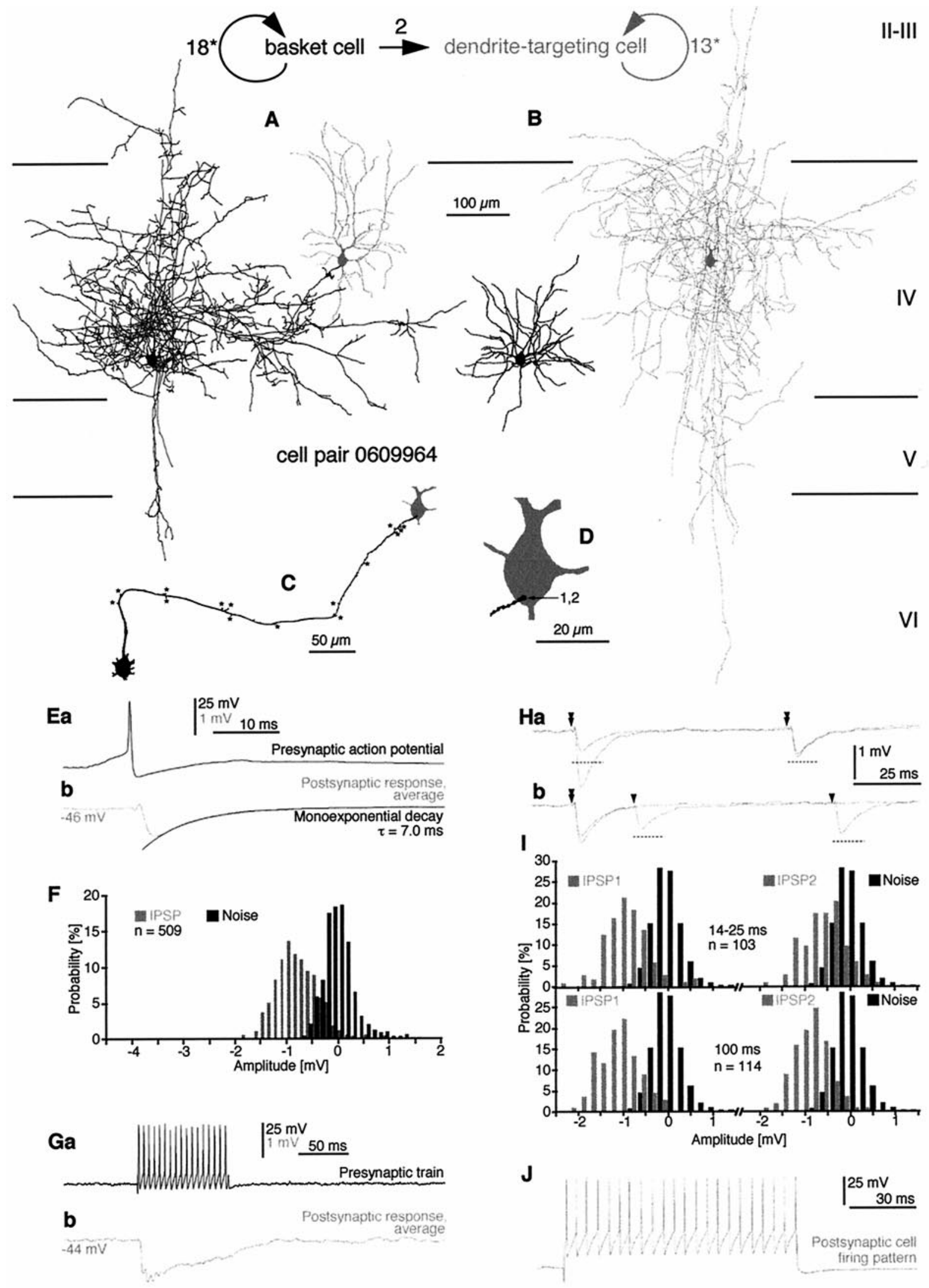

Figure 2. Physiologically and anatomically identified BC-to-DTC connection in area 17. The sketch and numbers on the top of the figure represent the synaptic and autaptic connectivity (straight arrow, synaptic connection; round arrows, autaptic connections) in the cell pair. A, Axonal pattern of the presynaptic BC (black) and the dendritic arbor of the postsynaptic DTC ( gray) that was located at the margin of the presynaptic axonal arbor are shown. $B$, The axonal arbor of the postsynaptic DTC ( gray) did not overlap with the dendritic tree of the presynaptic BC (black). C, (Figure legend continues). 
electron microscopy to correspond to synaptic boutons, was counted during the drawing procedure. Although in some cases the axons of different types of interneuron within the same slice could be differentiated based on anatomical criteria alone (see Results), each axonal branch presented in the reconstructions was followed back to the parent soma. Within a specimen, the average proportion of filled axonal varicosities that could not be traced back to the axon initial segments was $8.5 \pm 3.7 \%$. However, in the presented cases, all axonal branches that formed a putative contact site on a filled soma or dendrite could be followed back to the parent soma. Because of the location of pre- and postsynaptic cells in the central portion of the slice, we could obtain nearly complete reconstructions of the dendritic arbors in each case. The entire somatodendritic surface of both recorded cells was investigated for close appositions with filled axons, each of which could be traced back to the respective parent soma. Light micrographs at different focal depths were taken from all such close appositions and from characteristic axonal and dendritic patterns.

After light microscopic analysis, axon-rich areas, including all layers covered by the axonal field, were re-embedded for ultrathin sectioning. Serial sections were cut and mounted on single-slot Formvar-coated copper grids and contrasted with lead citrate. The sections were scanned in the electron microscope, and all biocytin-filled axonal profiles were followed until they formed synaptic contacts. Because all profiles were followed and the plane of the section randomly cuts through the axonal branches, the above procedure ensured a random sample of postsynaptic targets. Each presynaptic terminal under scrutiny was completely examined in serial sections to establish the number of synapses it formed. The tracing of serial sections was also useful to distinguish between dendritic spines and small caliber dendritic shafts as postsynaptic elements. In some cases, when the tracing was not feasible, small diameter postsynaptic profiles containing mitochondria and/or microtubules were classified as dendritic shafts, although infrequently spines may also contain mitochondria (Anderson et al., 1994; G. Tamás, E. H. Buhl, and P. Somogyi, unpublished observations). Subsequently, all light microscopically detected sites of close appositions between filled axons and labeled somata or dendrites were followed in serial electron microscopic sections. Although in some cases the identification of the postsynaptic membrane specialization was not possible because of the electron-opaque reaction endproduct, we verified synaptic junctions based on the following criteria: (1) vesicle accumulation at the junctional site in the presynaptic axonal varicosity and (2) rigid membrane apposition between the preand postsynaptic element with a characteristic widening of the extracellular space. When the plane of the section was not perpendicular to the junctional membranes, the synaptic cleft could be recognized by tilting the section using the goniometer of the electron microscope. Direct membrane apposition alone did not predict the presence of a synaptic junction. Moreover, all filled somata were serially sectioned completely for electron microscopic analysis to check for the presence of axonal branches that may have been obscured by the opaque cell bodies. The distances of synaptic junctions from the respective soma were measured along the dendrites on two-dimensional reconstructions.

Statistics. The nonparametric Mann-Whitney $U$ test was applied to compare the properties of the different cell types. Unless indicated otherwise, results are given as the mean $\pm \mathrm{SD}$.

\section{RESULTS}

A total of nine smooth dendritic interneurons were studied, resulting in the analysis of 10 paired unitary interactions. They were comprised of three synaptically coupled pairs of interneurons and a network of three reciprocally interconnected GABAergic cells. During physiological recordings, neurons were tentatively identified according to their firing characteristics. Despite differences in the properties of distinct cell types, it was not possible to discriminate reliably between interneurons on physiological grounds; therefore anatomical identification of cell types was considered to be essential. Because the primary aim of our study was the definition of synaptic interactions between different types of smooth dendritic cells, we used a well-established classification scheme according to which cells are grouped with respect to their differential innervation of postsynaptic membrane domains (Szentagothai and Arbib, 1974; Somogyi, 1989; Tamas et al., 1997b). The GABAergic nature of basket cells is well established (Somogyi and Soltesz, 1986). Dendrite-targeting cells, a class of cell defined recently on the basis of the placement of their synaptic terminals on proximal dendrites (Tamas et al., 1997b), make synaptic junctions (type II; Gray, 1959) and evoke postsynaptic responses similar to those of basket cells (Tamas et al., 1997b) and therefore are also likely to be GABAergic, but this has not been demonstrated directly. Double bouquet cells also establish Gray's type II synapses and elicit fast IPSPs with a reversal potential close to the chloride equilibrium potential (Tamas et al., 1997b); therefore they are very likely to use GABA as a transmitter.

\section{Distinct categories of GABAergic interneurons}

Based on random samples of postsynaptic target elements $(n=$ 75), five smooth dendritic cells were identified as "basket cells" (BCs) innervating mainly somata $(52.8 \pm 12.8 \%)$ and dendritic shafts $(44.3 \pm 11.5 \%)$ and, on occasion, dendritic spines and axon initial segments $[1.3 \pm 3.0$ and $4.4 \pm 9.9 \% ; n=26$ synapses in this study; synaptic target data for three cells have been reported by Tamas et al. (1997a)]. Sampling of the target elements could not be performed randomly from the postsynaptic cell of cell pair 1412941 (Fig. 1) because only the main axonal trunks and three bouton-forming collaterals were recovered from the axon. The recovered boutons made synapses with three somata $(43 \%)$, three dendritic shafts (43\%), and one dendritic spine (14\%); therefore this neuron was also classified as a BC. All BCs were characterized by nonspiny, prominently beaded dendrites that bifurcated

\footnotetext{
The route of the presynaptic axon (black) to synaptic boutons on the postsynaptic cell ( gray) is shown. Branch points are indicated by asterisks. D, Location of electron microscopically verified synaptic junctions between the BC and DTC is shown. A single presynaptic bouton formed two separate synaptic release sites on the soma of the postsynaptic cell. $E$, Action potentials $(\sim 1 \mathrm{~Hz})$ of the $\mathrm{BC}(E a)$, evoked by a depolarizing current pulse, resulted in a short-latency, fast IPSP $(E b)$ with a mean amplitude of $-0.77 \pm 0.40 \mathrm{mV}$ in the DTC, which was held at a membrane potential of $-46 \mathrm{mV}$. F, Amplitude distributions of IPSPs and baseline noise in the DTC show the absence of a distinct failure peak in the IPSP distribution. $G$, Summation and fading of IPSPs evoked by repetitive presynaptic firing are shown. High frequency nonaccommodating firing of the BC ( $G a$; single sweep) evoked by a depolarizing current pulse $(0.5 \mathrm{nA})$ produced an increase in the IPSP amplitude only after the first two APs; then the effect decreased to a plateau at $\sim 53 \%$ of the peak amplitude $(G b)$. Ha, When using a PP protocol (black arrowheads mark presynaptic APs), PP depression was apparent, relative to the average of all first IPSPs, regardless whether first IPSPs were smaller than 1 or larger than $1.5 \mathrm{mV}$ in amplitude. $\mathrm{Hb}$, Effect of AP intervals (14-25 and $100 \mathrm{msec})$ on the degree of PP depression is shown. As a reference, dotted lines indicate the mean amplitude of the respective conditioning 1st IPSPs. Note slight adjustments of their vertical position, owing to slight amplitude differences of IPSP1s, as well as additional baseline offsets caused by the ongoing decay of IPSP1. I, Amplitude distributions of first (IPSP1) and second (IPSP2) IPSPs and corresponding noise measurements in PP experiments with different interspike intervals (top, $14-25 \mathrm{msec}$; bottom, $100 \mathrm{msec}$ ) are shown. Note the overall shift of second IPSPs toward smaller amplitudes at $14-25$ msec intervals. $J$, In response to depolarizing current pulses of $0.6 \mathrm{nA}$, the postsynaptic DTC fired nonaccommodating trains of APs followed by a deep, fast AHP. The synaptic coupling between the two cells in the reverse direction was also tested physiologically, and in agreement with the anatomical observations, no synaptic interaction could be detected. Light microscopic analysis, however, indicated that both neurons were massively self-innervating and formed 18 and 13 putative autapses (asterisks in sketch on top; only one putative autapse was electron microscopically tested and verified).
} 


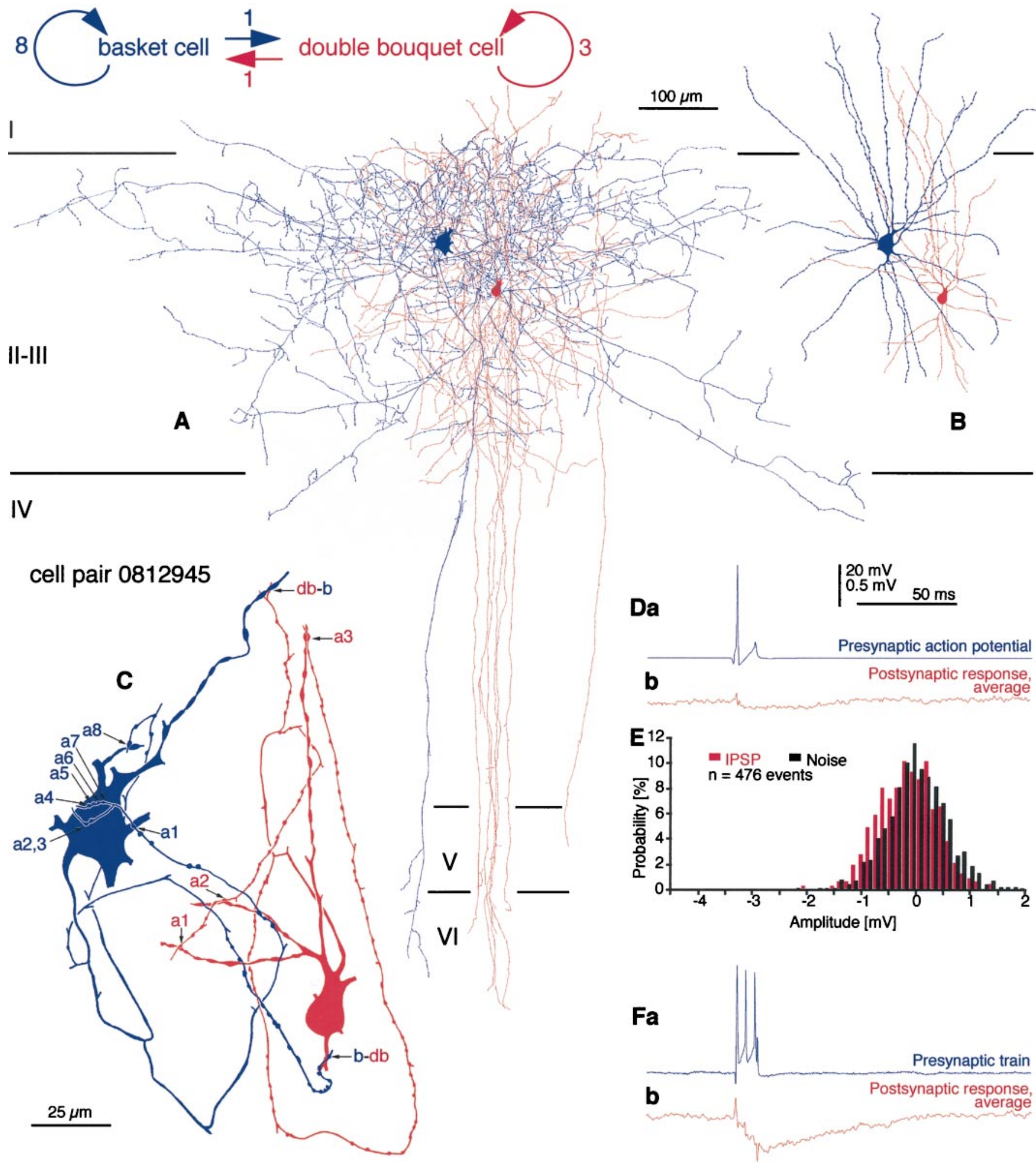

Figure 3. Reciprocally connected BC-to-DBC pair in area 17. The sketch and numbers on the top of the figure represent the synaptic and autaptic connectivity (arrows) in the cell pair. $A, B$, Axonal $(A)$ and dendritic $(B)$ arborization of the presynaptic $\mathrm{BC}(b l u e)$ and the postsynaptic DBC (red) is shown. $C$, The route of axonal branches of the $\mathrm{BC}$ and $\mathrm{DBC}$ to boutons establishing synaptic and autaptic junctions, all of which were verified by electron microscopy, is shown. The BC innervated the DBC through a single synapse $(b-d b)$ and formed eight autaptic junctions (blue; $a 1-a 8)$. One of the autaptic terminals formed two separate synaptic junctions $(a 2,3)$. The DBC established one synaptic junction on the BC $(d b-b)$ and innervated itself via three autapses (red; a1-a3). Note that when the release sites formed by the BC are compared with those established by the DBC, the former targeted proximal parts, whereas the latter innervated more distal regions of the cell. $D-F$, Synaptic coupling could be tested electrophysiologically from the BC to the DBC. $D$, Action potentials $(\sim 1 \mathrm{~Hz})$ of the BC $(D a)$ resulted in a short-latency IPSP $(D b)$ with a mean amplitude of $-0.13 \pm 0.53 \mathrm{mV}$ with the DBC being depolarized to a membrane potential of $-57 \mathrm{mV}$. E, Amplitude distributions of IPSPs and baseline noise in the DBC show a slight shift of the IPSP distribution relative to the noise. $F$, Brief trains of presynaptic APs $(F a)$ elicited a summated response in the DBC $(F b)$ at a membrane potential of $-57 \mathrm{mV}$. 


\begin{tabular}{|c|c|c|c|c|}
\hline Connection & $\mathrm{BC}$ to $\mathrm{BC}$ & BC to DTC & $\mathrm{BC}$ to $\mathrm{DBC}$ & $\mathrm{DBC}$ to $\mathrm{BC}$ \\
\hline \multicolumn{5}{|l|}{ Number of connections studied } \\
\hline Light and electron microscopy & 3 & 1 & 3 & 3 \\
\hline Synaptic effect recorded & 2 & 1 & 2 & \\
\hline \multicolumn{5}{|l|}{ Light microscopic prediction } \\
\hline \multicolumn{5}{|l|}{ Number of close appositions } \\
\hline On the soma & $1.3 \pm 0.6$ & 1 & $0.3 \pm 0.6$ & $0.0 \pm 0.0$ \\
\hline On dendrites & $6.7 \pm 4.6$ & 0 & $3.7 \pm 1.5$ & $4.3 \pm 3.2$ \\
\hline Total & $8.0 \pm 4.4$ & 1 & $4.0 \pm 1.7$ & $4.3 \pm 3.2$ \\
\hline \multicolumn{5}{|l|}{ Electron microscopic verification } \\
\hline \multicolumn{5}{|l|}{ Number of synapses } \\
\hline On the soma & $5.0 \pm 3.6$ & 2 & 0 & 0 \\
\hline On dendrites & $7.3 \pm 3.2$ & 0 & $1.7 \pm 0.6$ & $3.0 \pm 1.7$ \\
\hline Total & $12.3 \pm 6.8$ & 2 & $1.7 \pm 0.6$ & $3.0 \pm 1.7$ \\
\hline \multicolumn{5}{|l|}{$\%$ of light microscopic prediction } \\
\hline On the soma & $433.3 \pm 404.1$ & 200 & & \\
\hline On dendrites & $122.3 \pm 29.3$ & & $55.0 \pm 39.7$ & $77.8 \pm 48.1$ \\
\hline Total & $153.5 \pm 13.3$ & 200 & $53.3 \pm 41.6$ & $77.8 \pm 48.1$ \\
\hline Distance from the soma $(\mu \mathrm{m})^{*}$ & $15.8 \pm 12.4$ & 0 & $25.7 \pm 18.9$ & $42.9 \pm 19.2$ \\
\hline
\end{tabular}

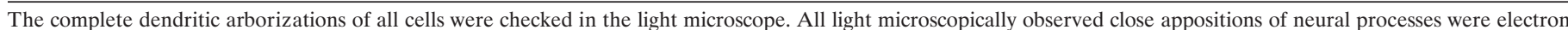

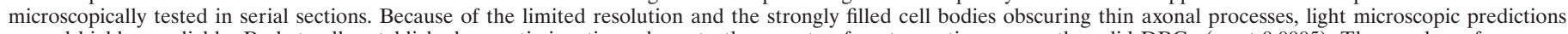

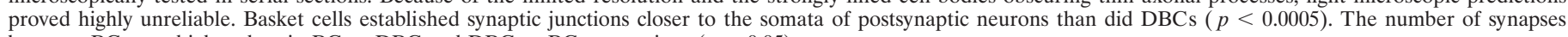
between BCs was higher than in BC-to-DBC and DBC-to-BC connections $(p<0.05)$.

* Measured as a two-dimensional projected distance.

near the soma into secondary and tertiary branches. With the exception of cell 0609964, which innervated mainly layer IVb, thus corresponding to previously described clutch cells (Kisvarday et al., 1985), BCs distributed their axons predominantly in layers II-III and sent descending collaterals to layers V and VI. Detailed descriptions of the morphological characteristics of BCs have been published (Gilbert and Wiesel, 1979; Martin et al., 1983; Somogyi et al., 1983; Kisvarday et al., 1985; Tamas et al., 1997b). The BCs had a mean resting membrane potential of $-63.0 \pm 11.4 \mathrm{mV}(n=6)$ and an input resistance of $41.7 \pm 14.2$ $\mathrm{M} \Omega(n=4)$ and fired APs with amplitudes of $48.1 \pm 14.6 \mathrm{mV}$ $(n=6)$.

Based on light microscopic appearance and its characteristic postsynaptic target profile ( $85 \%$ on dendritic shafts; $15 \%$ on dendritic spines; $n=13$ synapses), one neuron was identified as a "dendrite-targeting cell" (DTC; Fig. 2). The description of other examples of this cell type is given by Tamas et al. (1997a). The beaded dendrites of this cell formed a radially elongated dendritic field (Fig. 2A), and its axonal cloud was composed of radially running main trunks and thick, necklace-like collaterals that were studded with large boutons that followed mainly arcadic or radial routes. The DTC had a resting membrane potential of $-64 \mathrm{mV}$ and an input resistance of $80 \mathrm{M} \Omega$ and fired overshooting APs with a mean amplitude of $81.8 \mathrm{mV}$.

The characteristic axonal arborization of two neurons spanned all cortical layers in a horsetail-like manner (see Figs. 3, 5). Therefore, these cells were identified as "double bouquet cells" (DBCs) (Ramon y Cajal, 1894; Somogyi and Cowey, 1981; Tamas et al., 1997b). The samples of postsynaptic target elements and the presence or absence of autapses on the two cells were reported earlier (Tamas et al., 1997b,c). In the present study, we deal with their connections with other GABAergic cells, which have been analyzed since the previous publications. Although both cells were classified as DBCs, they showed a number of dissimilar characteristics and may thus represent subtypes of the
DBC class. The dendrites of cell 2402934 (see Figs. 5, 6) were thin and unbeaded and had branching points relatively distal (up to $\sim 100 \mu \mathrm{m}$ ) from the soma. In addition, the proximal dendrites received characteristic invaginated asymmetrical synapses with a wide, nonsynaptic membrane apposition between the dendrite and the presynaptic terminals. The axon had small, thorn-like varicosities with thin interbouton segments and targeted preferentially dendritic spines and less frequently dendritic shafts [67.7 and 32.3\%, respectively; $n=31$; data from Tamas et al. (1997a)]. In contrast, the dendrites of the DBC 0812945 (Fig. 3) were strongly beaded; they branched in the proximity of the soma and did not receive invaginated type I synapses. Furthermore, the axon of this cell formed larger terminals and thicker interbouton segments, and dendritic shafts were more frequent in the target element sample than in spines [62.5 and 37.5\%, $n=24$; data from Tamas et al. (1997b)]. The DBCs 0812945 and 2402934 had resting membrane potentials of -65 and $-81 \mathrm{mV}$, respectively; the input resistance of cell 0812945 was $30 \mathrm{M} \Omega$; and they fired APs with amplitudes of 66.5 and $88.2 \mathrm{mV}$, respectively.

\section{Anatomical analysis of unitary interactions}

Ten unitary connections were fully analyzed with correlated light and electron microscopy. All of the synaptic links involved BCs, with the latter innervating other BCs ( $n=3$ connections), DBCs $(n=3)$, and a DTC. In addition, we studied three DBC-to-BC connections. In four out of five cell pairs, having fully recovered axons and dendrites of both neurons, synaptic connections were reciprocal. A total of 53 synaptic junctions could be verified between the recorded neurons, with the average number of release sites per unitary connection being $5.3 \pm$ 5.9. However, significant differences emerge when comparing the number and location of unitary synapses between particular directions of synaptic links (Table 1). The subcellular domain preference of the presynaptic GABAergic cells was reflected in the differential placement of unitary terminals on individual postsynaptic neu- 

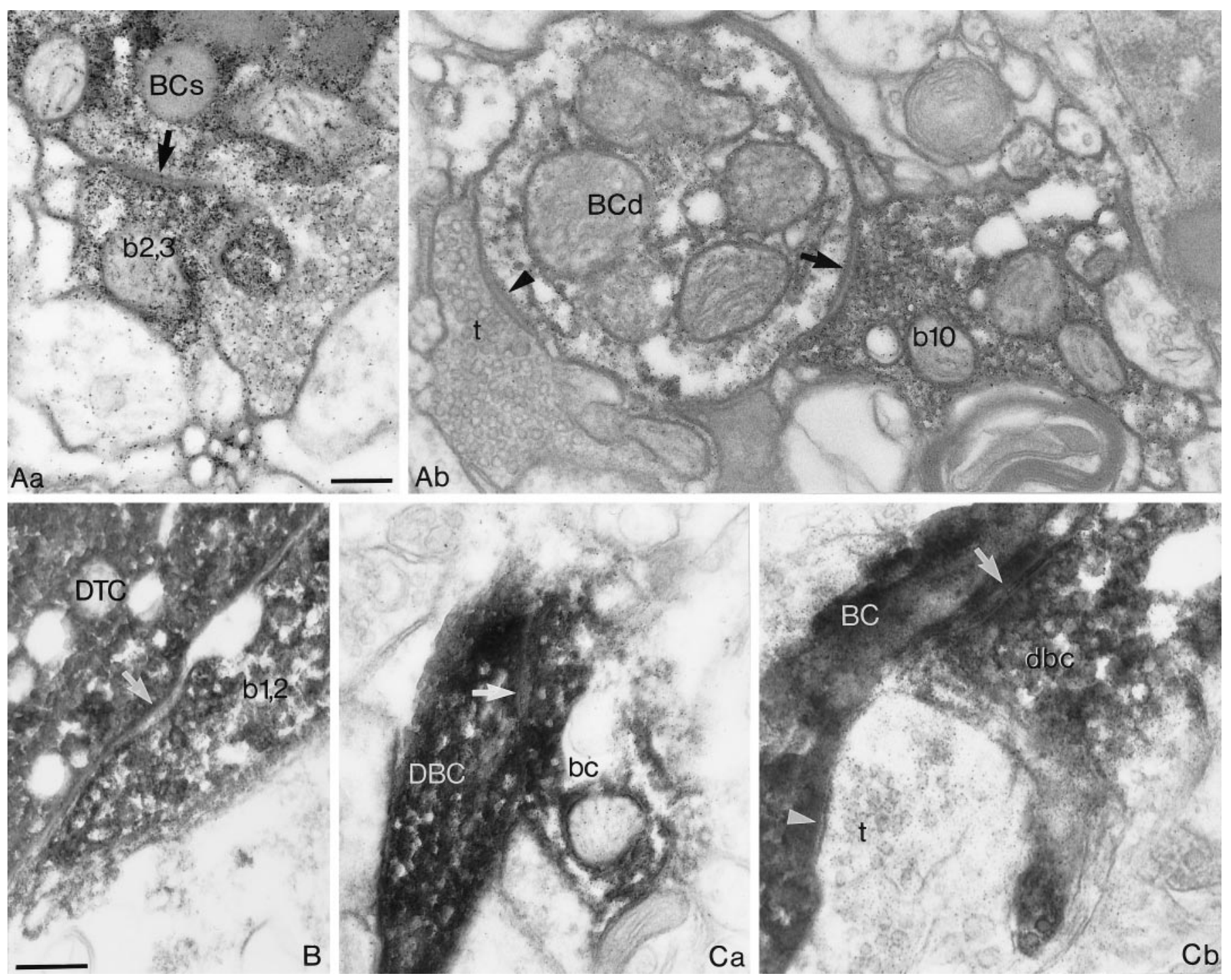

Figure 4. Electron microscopic evidence of synaptic junctions between GABAergic neurons shown in Figures 1-3. A, Synapses between the two BCs illustrated in Figure 1. $A a$, One of the two synaptic junctions (arrow) established by a bouton $(b 2,3)$ of the presynaptic BC on the soma $(B C s)$ of the postsynaptic $\mathrm{BC}$ is shown. $A b$, An axonal terminal of the presynaptic $\mathrm{BC}(b 10)$ forms a synapse (arrow) on a dendrite $(B C d)$ of the postsynaptic $\mathrm{BC}$. An unlabeled terminal $(t)$ also establishes a synaptic junction (arrowhead). B, One of the two synaptic junctions (arrow) formed by the same bouton (b1,2) of the presynaptic BC on the soma of the DTC illustrated in Figure 2. $C$, The two synaptic junctions from the reciprocally connected BC-to-DBC pair shown in Figure 3. $\mathrm{Ca}$, A bouton $(b c)$ of the $\mathrm{BC}$ establishes a synapse (arrow) on a dendrite of the $\mathrm{DBC}$. $\mathrm{Cb}$, In the reverse direction, a bouton $(d b c)$ of the DBC formed a synaptic junction (arrow) on a dendrite of the BC. A neighboring unlabeled terminal $(t)$ also established a synapse (arrowhead) on the postsynaptic dendrite. The numbering of presynaptic boutons corresponds to that in Figures $1 D, 2 D$, and $3 C$, respectively. Scale bars, $0.2 \mu$ m, with $B$ and $C$ at the same magnification.

rons. Moreover, the autaptic self-innervation reported earlier (Tamas et al., 1997c) is illustrated for several of the analyzed interactions (see schematic presentation in Fig. 2 and illustrations in Figs. 3, 6); for a more comprehensive description, see Tamas et al. (1997b).

\section{$B C$-to-BC connections}

A BC-to-BC pair (1412941; Figs. 1, 4) and the connectivity between two BCs of a trineuronal network (2402934; Figs. 5-7) provided evidence of monosynaptic interactions of neighboring ( $\sim 40-130 \mu \mathrm{m})$ BCs in the neocortex, as reported earlier for BCs at larger lateral distances (Kisvarday et al., 1993). Reciprocity could be tested and ascertained in only one of the cell pairs (2402934) because of the inadequate axonal labeling of the postsynaptic BC of cell pair 1412941. Consistently, BC-to-BC $(n=3)$ interactions were the strongest of the cortical unitary interneuron-interneuron connections analyzed in this study. The number of synapses (Table 1) between BCs was significantly higher than that in BC-to-DBC and/or DBC-to-BC connections ( $p<0.05$ for both; Mann-Whitney $U$ test). The electron microscopically verified synaptic junctions mediating BC-to-BC interactions were located either on somata $(n=15)$ or on dendrites $(n=22)$, with their overall subcellular placement being significantly closer to the soma than that in DBC-to-BC connections ( $p<0.0005$; Mann-Whitney $U$ test; Table 1$)$. In one instance (pair 1412941), four axonal branches originated from the same 10th order collateral and innervated the postsynaptic BC (Fig. $1 C, D)$. Three presynaptic boutons established four synapses on the soma (Figs. $1 D$; numbers $1 ; 2,3 ; 4 ; 4 A a$ ), four secondary 


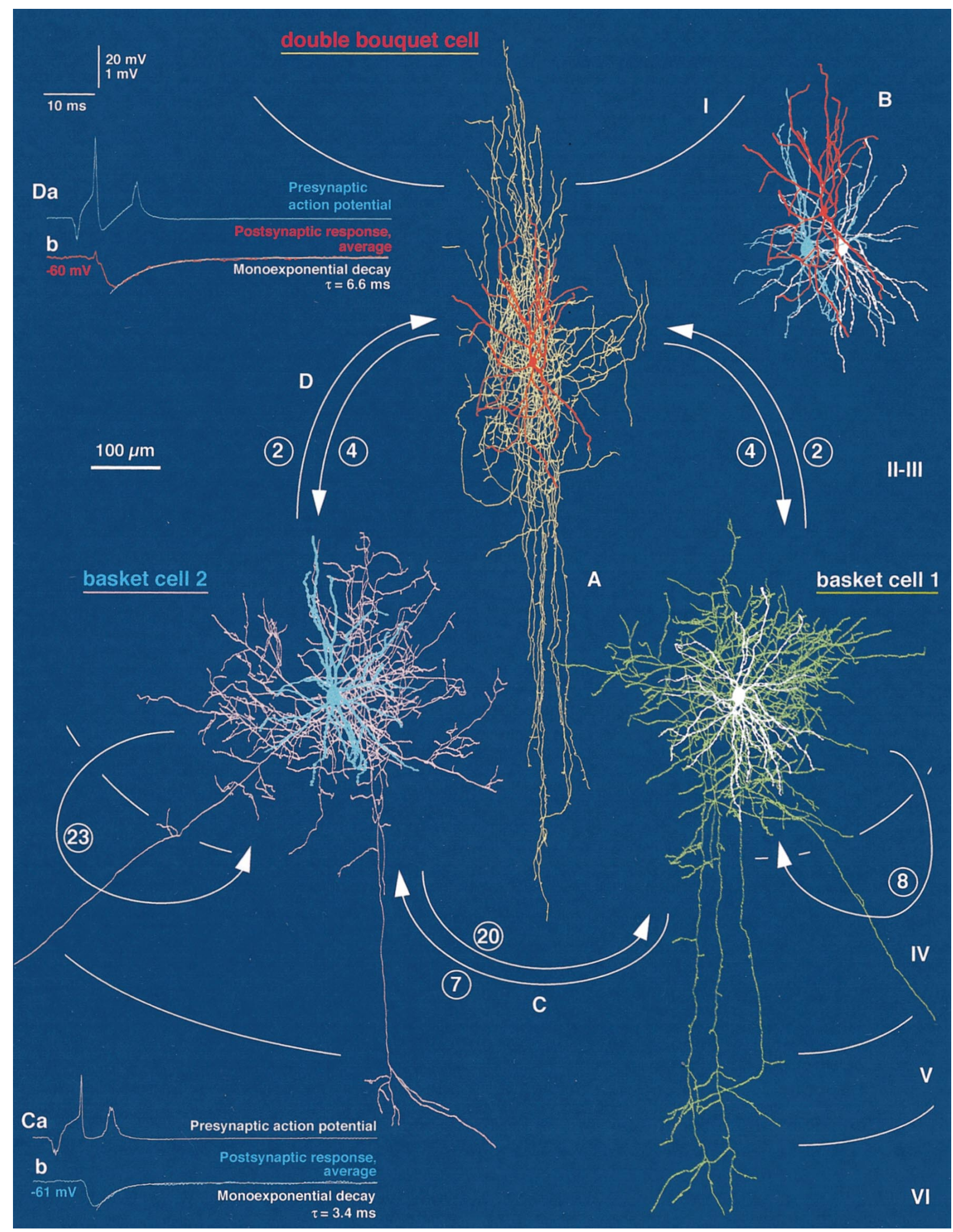

Figure 5. Reciprocally interconnected network of two BCs and a DBC in the medial bank of area 17. A, Light microscopic reconstructions of the three interneurons [basket cell 1 (BC1), white soma and dendrites, green axon; basket cell 2 ( $\mathrm{BC} 2)$, blue soma and dendrites, pink axon; double bouquet cell, red soma and dendrites, yellow axon] are shown. Arrows indicate the identified directions of connections (for details, see Figs. 6, 7); the numbers of synapses are given in circles. Each cell was in reciprocal connection with the other two, and the two BCs also innervated themselves. For the display of overlapping axonal and dendritic arborizations of the cells, layer III is shown expanded, maintaining the position of layer I relative to the DBC and that of layers IV-VI to the BCs. $B$, The topographically correct position of dendritic trees is illustrated. $C, D$, Functional synaptic coupling could be tested electrophysiologically in only two directions. Action potentials $(1-2 \mathrm{~Hz})$ of $\mathrm{BC} 1(C a)$ and $\mathrm{BC} 2(\mathrm{Da})$ resulted in short-latency, fast IPSPs $(C b, D b)$ with mean amplitudes of -0.59 and $-0.70 \mathrm{mV}$ in $\mathrm{BC} 2$ and $\mathrm{DBC}$, respectively. The latter were held at membrane potentials of -61 and $-60 \mathrm{mV}$. 


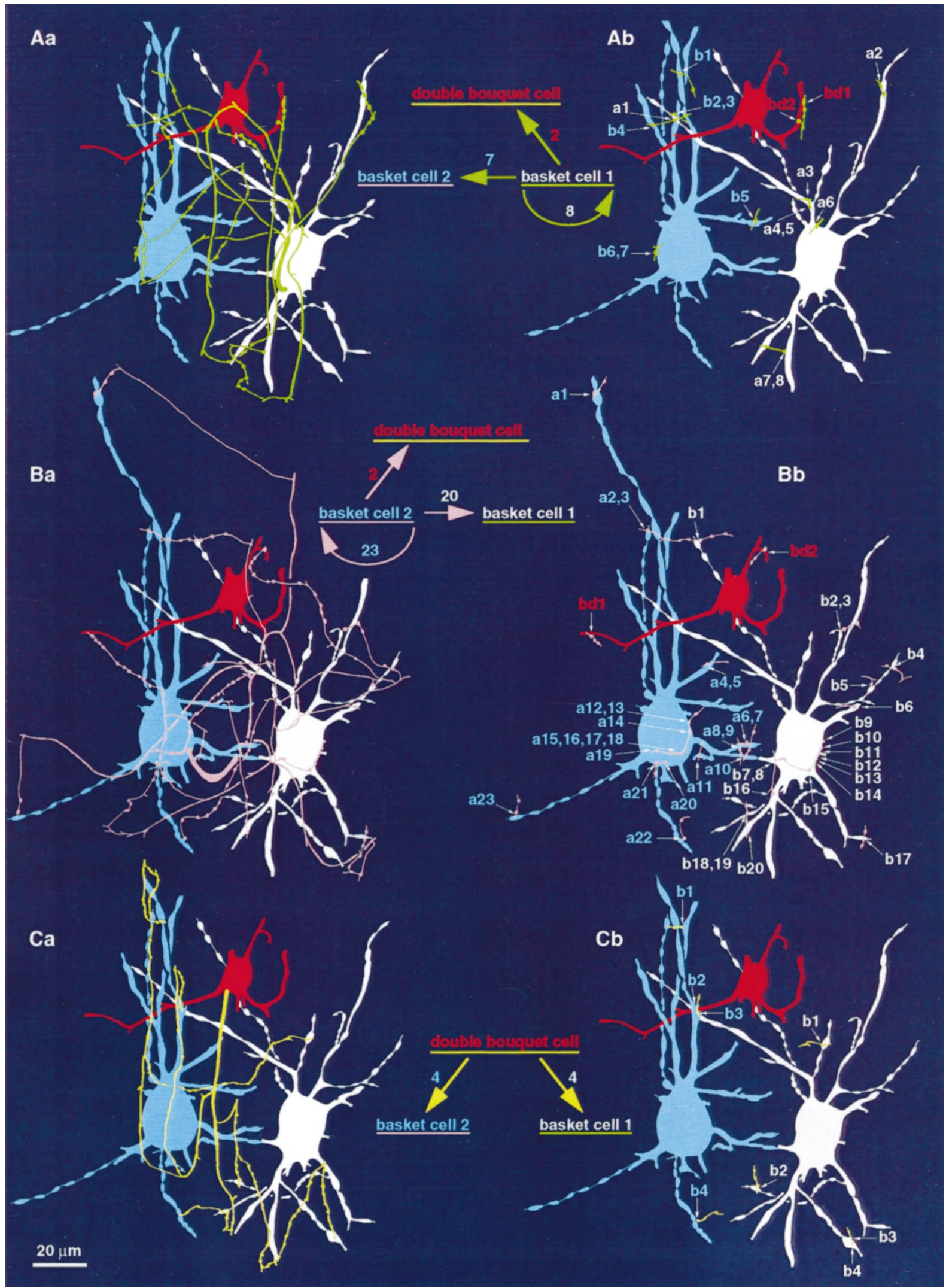

Figure 6. Route of axons to synaptic and autaptic boutons and subcellular placement of synapses and autapses within the trineuronal network established by two BCs and a DBC presented in Figure 5. A-C, Within the network. a total of 70 synapses and autapses were identified with correlated light and electron microscopy. Each panel shows a single presynaptic axon and all dendritic branches innervated by the cell. $A$, Synaptic and autaptic output of $\mathrm{BC} 1 . A a$, The route of the axon to its identified targets is shown (green). Ab, $\mathrm{BC} 1$ established one somatic (white; a6) and seven dendritic (a1-a5; a 7,8) autapses, innervated BC2 via seven synaptic junctions (blue; two on the soma, b6,7; five on dendrites, b1-b5), (Figure legend continues). 
dendrites were targeted by three en passant boutons forming five synapses (Fig. $1 D$; numbers 5,$6 ; 7 ; 8,9$ ), and one en termineaux bouton formed a single synaptic junction (Figs. 1D; number 10; $4 \mathrm{Ab})$. The presynaptic terminals in the $\mathrm{BC} 1$-to-BC2 connection of the trineuronal network were formed by 4 th to 10 th order axonal branches (Fig. 6Aa), and they targeted the soma (Fig. 6Ab;b6,7) and a secondary (b5) and three tertiary $(b 1 ; b 2,3 ; b 4)$ dendrites. In the reverse direction, sixth to ninth order axon collaterals of $\mathrm{BC} 2$ (Fig. $6 B a$ ) terminated on the soma (Fig. $6 B b ; b 7-b 15$ ) and on two primary $(b 1 ; b 16)$, a secondary $(b 4 ; b 5)$, and four tertiary $(b 2,3$; $b 17 ; b 18,19 ; b 20)$ dendrites. The analysis of BC-to-BC pairs underlined the importance of electron microscopic (EM) examination of the connections. Without the complete EM assessment of postsynaptic somata, the overall number of somatic synapses would have been underestimated $(p<0.07)$. Light microscopic predictions of putative synaptic contacts sites on dendrites were also unreliable (Table 1).

\section{The BC-to-DTC interneuron pair}

The connection between the two layer IV neurons was found to be unidirectional, both anatomically and physiologically. The postsynaptic DTC was located at the margin of the BC axonal arborization, whereas the axonal cloud of the DTC did not overlap with the dendritic arbor of the BC (Fig. $2 A, B$ ). A single terminal bouton formed by a 16th order collateral of the presynaptic axon established two separate synaptic junctions on the basal pole of the DTC soma (Figs. 2C,D, $4 B$ ).

\section{$B C$-to-DBC interactions}

The analysis of a BC-to-DBC pair (0812945; Figs. 3, 4) and the connections from $\mathrm{BC} 1$ and $\mathrm{BC} 2$ to the $\mathrm{DBC}$ in the trineuronal network (2402934; Figs. 5-7) showed that BCs innervate neighboring $(\sim 50-100 \mu \mathrm{m})$ DBCs. Reciprocity could be tested and verified for the three BC-to-DBC cell pairs, all of which were located in layer III. As indicated above, BC-to-DBC interactions were mediated by a significantly smaller number of synaptic junctions than were BC-to-BC connections (Table 1). Although all electron microscopically verified synaptic junctions $(n=5)$ mediating BC-to-DBC interactions were exclusively on dendrites, their distance, when measured from the soma, was not significantly different from that of BC-to-BC connections $(p>0.1$; Table 1). In one instance, an en passant bouton of a seventh order collateral of the presynaptic BC (0812945; Fig. 3C) established a single synaptic junction on a primary basal dendrite of the postsynaptic DBC (Figs. 3C, 4). Both presynaptic terminals in the $\mathrm{BC} 1$-to-DBC connection of the trineuronal chain were formed by an 11th order axonal branch (Fig. 6Aa), and they targeted the same secondary dendrite (Fig. $6 A b ; b d 1 ; b d 2$ ). In the BC2-to$\mathrm{DBC}$ connection of the trineuronal chain, 9th and 10th order axon collaterals of $\mathrm{BC} 2$ (Fig. $6 B a$ ) terminated on a tertiary and a secondary dendrite, respectively (Fig. $6 B b ; b d 1 ; b d 2$ ).

\section{DBC-to-BC connectivity}

The interconnectivity of the above DBC-to-BC pair (0812945; Figs. 3,4 ) and the connections from the $\mathrm{DBC}$ to $\mathrm{BC} 1$ and $\mathrm{BC} 2$ in the trineuronal network (2402934; Figs. 5-7) confirm that DBCs innervate smooth dendritic cells as well as pyramidal cells (Somogyi and Cowey, 1981) and indicate that DBCs and BCs are reciprocally connected. The number of synaptic junctions mediating DBC-to-BC interactions was significantly smaller than that for BC-to-BC connections (Table 1). In addition, the electron microscopically verified synaptic junctions $(n=9)$ mediating DBC-to-BC interactions were exclusively on dendrites, and the distance of synapses, when measured from the soma (twodimensional projected distances), was significantly larger than that of release sites established by presynaptic basket cells $(p<$ 0.0005; Table 1). In one instance, an en passant bouton of a seventh order collateral of the DBC (0812945; Fig. 3C) established a single synaptic junction on a fourth order dendrite of the postsynaptic BC (Figs. 3C, 4), whereas the presynaptic terminals in the DBC-to-BC1 connection of the trineuronal chain were formed by fifth to ninth order axonal branches (Fig. 6Ca), and they targeted three secondary dendrites (Fig. $6 \mathrm{Cb}$; white $b 1 ; b 2$; $b 3-b 4)$. Finally, six to ninth order axon collaterals of the DBC (Fig. 6Ca) terminated on two secondary dendrites of BC2 (Fig. $6 C b$; blue b1-b3; b4).

\section{Physiological properties of the recorded interactions}

From 10 of the anatomically reconstructed connections described above, a total of five could be physiologically tested, and in each case, action potentials evoked in the presynaptic interneuron evoked a unitary IPSP in the postsynaptic cell. All of the synaptic effects were elicited by presynaptic BCs $(n=5)$ and recorded in postsynaptic interneurons, being comprised of two BCs (Figs. 1, 5), a DTC (Fig. 2), and two DBCs (Figs. 3, 5).

\section{Kinetics of unitary IPSPS}

All presynaptic BCs elicited short-latency $(<1.5 \mathrm{msec})$ IPSPs, with fast rise and decay kinetics, regardless of the postsynaptic cell type (Figs. $1 E, 2 E, 3 D, 5 C, D)$. Reversal potentials, indicating that chloride was probably the major charge carrier, were -66.9 $\mathrm{mV}$ for a postsynaptic BC (1412941; Fig. 1) and $-72.9 \mathrm{mV}$ for the DTC (Fig. 2), as extrapolated from hyperpolarizing IPSPs measured at membrane potentials ranging from -58 to $-49 \mathrm{mV}$ and -76 to $-44 \mathrm{mV}$, respectively. Apart from the IPSP elicited by the BC in the DBC (Fig. 3$)$, the decay phase of unitary IPSPs $(n=4)$ could be adequately fitted with a single exponential function, with a mean time constant of $5.6 \pm 1.6 \mathrm{msec}$ (range, $3.4-7.0 \mathrm{msec}$ ) being similar to the decay time constant of somatically injected current pulses $(5.9 \pm 3.4 \mathrm{msec}$; range, $3.6-11.6 \mathrm{msec} ; p=0.46)$. Unitary mean IPSP conductances could be calculated for a BCto-BC (1412941; $n=10$ synapses) and the BC-to-DBC ( $n=2$ synapses) interaction and were 5.735 and $0.373 \mathrm{nS}$, respectively [for details, see Ginsborg (1973) and Benardo (1994)]. Although we have not obtained pharmacological evidence, the kinetics of unitary IPSPs evoked in both pyramidal (Tamas et al., 1997b) and smooth dendritic neurons is compatible with the properties of $\mathrm{GABA}_{\mathrm{A}}$ receptor-mediated synaptic responses (Avoli, 1986; Connors et al., 1988; Benardo, 1994; Deuchars and Thomson, 1995).

Average IPSP amplitudes were $919 \pm 863 \mu \mathrm{V}(n=5)$ and

\footnotetext{
and established two synapses on the same dendritic segment of the DBC (red; bd1; bd2). B, Synaptic and autaptic output of BC2. Ba, The route of the axon to its identified targets is shown (pink). Bb, BC2 formed 10 somatic (blue; a12-a21) and 13 dendritic $(a 1-a 11 ; a 22 ; a 23)$ autapses, innervated $\mathrm{BC} 2$ via 20 synaptic junctions (white; 9 on the soma, $b 7-b 15 ; 11$ on dendrites, $b 1-b 6$ and $b 16-b 20$ ), and established two synapses on dendrites of the DBC (red; $b d 1 ; b d 2)$. $C$, Synaptic output of the DBC. $C a$, The route of the axon to $\mathrm{BC} 1$ and $\mathrm{BC} 2$ is shown (yellow). $C b$, The DBC innervated $\mathrm{BC} 1 \mathrm{via}$ four synapses on dendrites (white; b1-b4) and established four synapses on dendrites of the BC2 (blue; b1-b4). Grouped numbers indicate boutons establishing more than one separate synaptic or autaptic junction.
} 

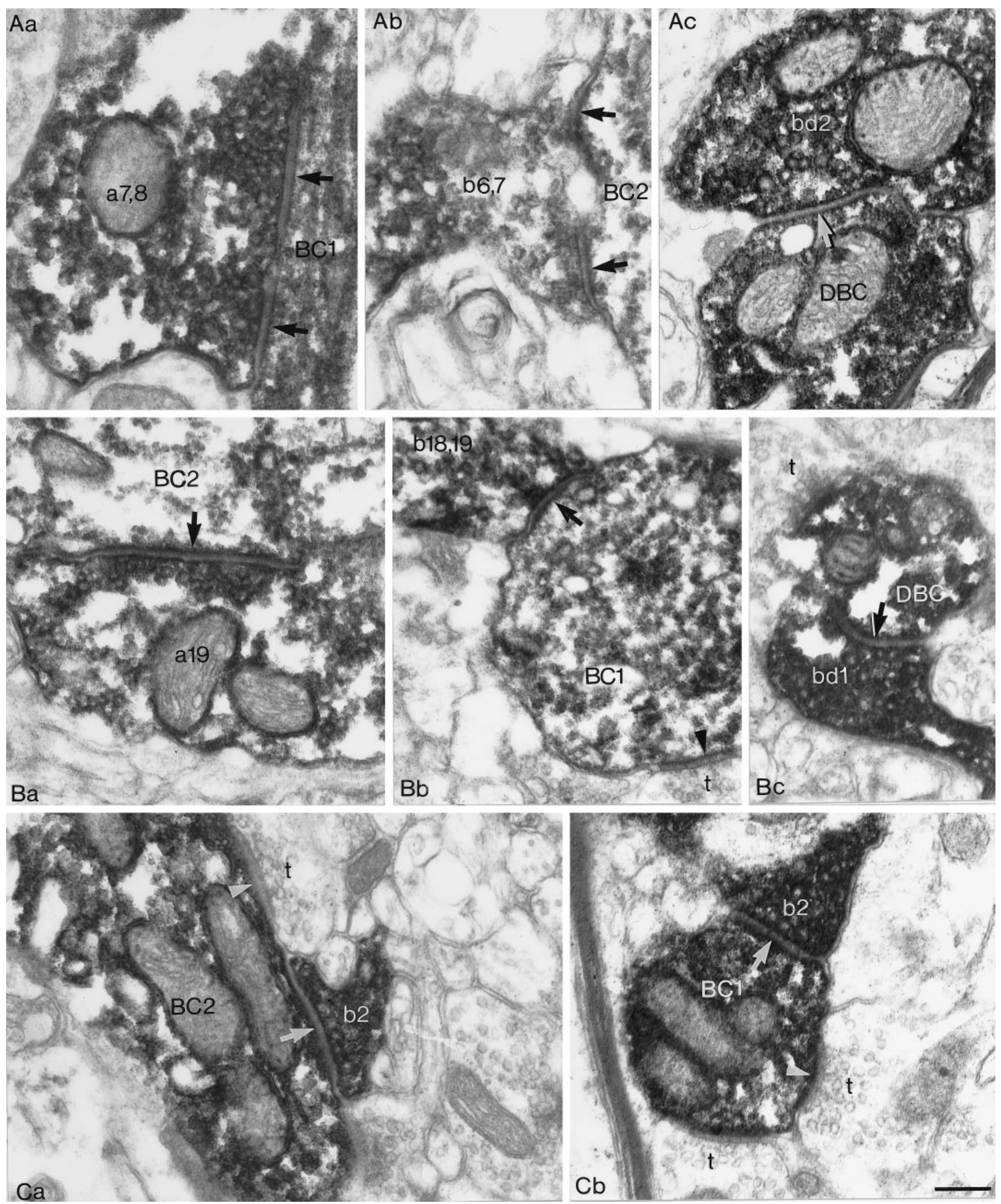

Figure 7. Examples of electron microscopically verified synaptic and autaptic junctions within the trineuronal network of two BCs and a DBC presented in Figures 5 and 6. A, Synaptic and autaptic output of BC1. Aa, An axon terminal $(a 7,8)$ of $\mathrm{BC} 1$ establishes two separate autaptic junctions (arrows) on its own dendrite $(B C 1)$. $A b$, Two separate synaptic junctions (arrows) between a bouton $(b 6,7)$ of $\mathrm{BC} 1$ and the soma $(B C 2)$ of $\mathrm{BC} 2$ are shown. $A c, \mathrm{~A}$ bouton (bd2) of $\mathrm{BC} 1$ forms a synaptic junction (arrow) on a dendrite $(D B C)$ of the DBC. The convention of labeling presynaptic boutons corresponds to that of Figure $6 A b . B$, Synaptic and autaptic output of BC2. Ba, An axon terminal (a19) of BC2 establishes an autapse(Figure legend continues). 
varied from 133 to $2397 \mu \mathrm{V}$ at membrane potentials ranging between -46 and $-61 \mathrm{mV}$ (mean $\pm \mathrm{SD},-55.0 \pm 6.4 \mathrm{mV})$. The IPSPs elicited in BCs and in DBCs had an average amplitude of 1522 and $419 \mu \mathrm{V}$, respectively (for individual measurements, see Figs. 1, 3, 5), and the mean amplitude of the IPSP in the DTC was $771 \mu \mathrm{V}$ (Fig. 2). There was no significant correlation between the postsynaptic membrane potential and the amplitude of the IPSPs $(r=0.60 ; p=0.23$; Spearman correlation). There was a trend for unitary IPSP amplitudes to increase with the number of synaptic release sites mediating the interaction, although the correlation was not significant ( $r=0.67 ; p=0.18$; Spearman correlation). There were no obvious differences for different types of connections in the rise and decay kinetics of unitary IPSPs. Unitary IPSPs had a mean 10-90\% rise time of $1.51 \pm 0.53 \mathrm{msec}$ (range, $1.12-2.27 \mathrm{msec}$ ) and, measured at half-amplitude, a duration of $6.66 \pm 1.24 \mathrm{msec}$ (range, $5.03-8.00 \mathrm{msec}$ ).

\section{Amplitude distribution of unitary IPSPS}

At each interaction tested $(n=3)$, the amplitudes of unitary IPSPs fluctuated to some degree, although a significant portion of this variability may have been originating from the recording noise (see below). Generally, the amplitude of individual events fluctuated around the average of the postsynaptic response (Fig. $1 E c, d)$. For further analysis, amplitude histograms of unitary IPSPs and the corresponding baseline noise were constructed for those cases in which the number of unitary IPSPs was higher than 100 and the postsynaptic response remained stationary (Figs. $1 F$, $2 F, 3 E)$. In those three interactions, the mean ratio of IPSP amplitude and noise variances was $1.9 \pm 1.2$, ranging from 0.9 to 3.3. The overlap between the signal and noise distributions decreased with the increasing number of synaptic junctions mediating the events, with the absence of such overlap indicating the complete absence of transmission failures in the connection mediated by 10 release sites between two BCs (Fig. 1). Moreover, the absence of a distinct peak around the zero amplitude level suggests few, if any, response failures in a connection mediated by two synaptic junctions (Fig. 2, BC-to-DTC).

\section{Response summation and use-dependent depression of unitary IPSPS}

Unitary IPSP summation and use-dependent depression could be observed in the DTC when investigating the postsynaptic effect of high-frequency trains of action potentials elicited in the presynaptic BC (Fig. 2G). Summation of the initial two IPSPs increased the amplitude of single action potential-evoked events by $43 \%$. Although the presynaptic firing frequency remained constant, the response gradually declined to a relatively stationary level $\sim 53 \%$ of the maximum of the summed response. In comparison with single action potential-evoked events, the decay phase of a tetanically (17-18 APs) evoked unitary IPSP was somewhat prolonged (decay time constant $=17.1 \mathrm{msec}$ ).

To investigate more systematically the effect of activity preceding evoked responses, we applied a paired-pulse (PP) protocol by adjusting the depolarizing current pulse in the presynaptic cell to eliciting two action potentials only. Such data were obtained in two of the connections (Figs. 1, BC-to-BC, 2, BC-to-DTC). Interspike intervals were varied either by adjusting the current intensity or by delivering two successive current pulses and ranged from 10-28 and 14-200 msec in the BC-to-BC and BCto-DTC connections, respectively. The mean amplitudes of second IPSPs (IPSP2s) were 83 and $79 \%$ (mean $=81 \%$ ) of the corresponding conditioning first events, thus revealing statistically significant PP depression of both connections $(p<0.05)$ at mean interspike intervals of $15.0 \pm 5.8$ and $83.1 \pm 63.7 \mathrm{msec}$, respectively. The overall decrease of mean IPSP2 amplitudes was accompanied by an increase of the measured response variability, because the coefficient of variation (CV) of IPSP2s were 146 and $119 \%$ of the CV of the respective conditioning events (IPSP1s). Amplitude histograms showed a general shift of the distribution toward smaller amplitudes and a greater overlap with the noise measurements, suggesting a larger proportion of postsynaptic response failures (Fig. 2I). When the amplitudes of second IPSPs were plotted against those of the preceding events (data not shown), a statistically significant negative correlation was found in the BC-to-BC interaction $(r=0.49 ; p<0.01$; Pearson's $r$ table); thus large IPSP1s were followed more frequently by large IPSP2s and vice versa (Fig. $1 G c, d$ ). This trend was not apparent in the BC-to-DTC connection $(r=0.06 ; p>0.25$; Fig. $2 \mathrm{Ha})$. To assess the influence of the magnitude of the conditioning IPSP, single traces were presorted according to the amplitude IPSP1, separated into groups, and averaged. Finally, for each of the groups, the corresponding PP ratio was calculated, here taken as the ratio of averaged second IPSPs and the mean conditioning IPSP (i.e., the average of all first IPSPs). A value $>1$ would thus indicate the presence of PP facilitation, i.e., the second IPSP amplitude exceeding that of the mean conditioning first IPSP [for EPSPs, see Buhl et al. (1997)]. In the BC-to-BC connection, PP depression $(\mathrm{PP}$ ratio $=0.69)$ was apparent after IPSP1s smaller than $-2 \mathrm{mV}$ in amplitude (Fig. 1Gc) but not after IPSP1s larger than $-2 \mathrm{mV}$ (PP ratio $=1.00$; Fig. $1 G d$ ), i.e., large conditioning events decreased the degree of PP depression. The BC-to-DTC connection showed a similar trend, with $\mathrm{PP}$ ratios for conditioning events that were either smaller than 1 or larger than $1.5 \mathrm{mV}$ being 0.71 and 0.86 , respectively ( $p<0.02$; Fig. $2 \mathrm{Ha}$ ). For this connection, individual trials were also sorted with respect to the interspike interval and averaged. At all intervals tested, presorted and averaged EPSP2s were compared with the mean of the corresponding conditioning first events. It was apparent that PP depression predominated and PP ratios were $0.74,0.78$, and 0.90 at intervals of $14-25,100$, and $200 \mathrm{msec}$ (Fig. 2 $\mathrm{Hb}$ ). For each temporal increment, a prolongation of the interspike intervals was associated with a statistically significant increase of the PP ratio $(p<0.025)$.

\section{DISCUSSION}

This study demonstrates that neocortical GABAergic neurons receive GABAergic input from several distinct local sources and

\footnotetext{
(arrow) on its own soma (BC2). Bb, One of two synaptic junctions (arrow) formed by a single bouton $(b 18,19)$ of $\mathrm{BC} 2$ on a dendrite $(B C 1)$ of $\mathrm{BC} 1$ is shown. An unlabeled terminal $(t)$ also forms a symmetrical synapse (arrowhead) on the dendrite of $\mathrm{BC} 1 . B c, \mathrm{~A}$ bouton $(b d 1)$ of $\mathrm{BC} 2$ forms a synaptic junction (arrow) on a dendrite $(D B C)$ of the DBC. The labeling of presynaptic boutons corresponds to that of Figure $6 B b$. $C$, Synaptic output of the DBC. $C a$, An axon terminal (b2) of the DBC establishes a synaptic junction (arrow) on a dendrite (BC2) of BC2. A neighboring synapse (arrowhead) is formed by an unlabeled terminal $(t)$. $C b$, A bouton $(b 2)$ of the DBC forms a synapse (arrow) on a dendrite $(B C 1)$ of BC1. Two unlabeled terminals $(t)$ also make synapses (arrowhead) on the postsynaptic dendrite. The labeling of presynaptic boutons corresponds to that of Figure $6 \mathrm{Cb}$. Note that the axonal boutons of BCs are larger than are the terminals of the DBC. Scale bar, $0.2 \mu \mathrm{m}$.
} 
that, in addition to the innervation of spiny cell populations, individual GABAergic cells direct their output toward several classes of smooth dendritic cells. Intracolumnar reciprocal connections commonly occur between GABAergic neurons with similar and dissimilar efferent connectivity, and the intrinsic GABAergic interconnectivity is boosted by a high incidence of autaptic self-innervation. Interneuron-to-interneuron connections are heterogeneous, regarding both the number and subcellular placement of unitary synapses. Synapses between BCs are more numerous and located closer to the soma than are synapses mediating BC-to-DBC or DBC-to-BC interactions. Regardless of the postsynaptic target neuron, BCs evoke fast IPSPs in a reliable manner, particularly when mediated by several release sites. These results suggest a prominent role for BCs in governing the activity of local GABAergic neuronal circuits and, because of their divergent output, in linking excitatory and GABAergic networks.

\section{Differential patterns of interconnectivity in GABAergic networks}

We demonstrated that neocortical interneurons innervate other GABAergic cells via 1-20 electron microscopically verified synaptic junctions. Although the present sample is relatively small, significant differences emerged regarding connections between interneurons with distinct efferent target preferences; BCs innervated each other through a number of unitary release sites that is among the highest in the cortex, but BC-to-DBC and DBC-to-BC connections were mediated by a smaller number of synapses. The interconnections among a subclass of BCs was also noted from immunocytochemistry for cholecystokinin (Freund et al., 1986). The high incidence of autapses on BCs and on DTCs (Tamas et al., 1997c), the extensive interconnectivity between large BCs (Kisvarday et al., 1993), and the perisomatic concentration of symmetric synapses on layer IV basket cells (Freund et al., 1983; Ahmed et al., 1997) suggest a powerful GABAergic influence on BCs. Interactions between hippocampal BCs show a similar trend (Nunzi et al., 1985; Sik et al., 1995; Cobb et al., 1997). Therefore, $\mathrm{BC}$-to-BC interactions probably constitute a special link in the cortical network. Alternatively, the possibility may exist that there are preferential interconnections among all interneurons of the same type. Because of the large number of cell types that remain untested for potential interconnections within a class, this scenario cannot be excluded but seems unlikely.

If we assume that all neurons in the axonal field of an interneuron $(n=1272 \pm 414)$ are uniformly innervated, each postsynaptic cell would receive on average $4.31 \pm 1.28$ unitary GABAergic synapses, regardless of the presynaptic cell type (Tamas et al., 1997b). This value is well below that obtained for BC-to-BC pairs in this study and is in the upper range of the pooled BC-to-DBC and DBC-to-BC data. Therefore, it seems that within their axonal field BCs preferentially innervate other BCs. The overall degree of target cell selectivity could be even higher for large BCs, having a large, low-density axonal field (Somogyi et al., 1983; Kisvarday et al., 1993). Because we anatomically scrutinized all possible interactions for the number of synapses and detected physiologically connections with one or two release sites, the possibility is unlikely that our recordings were strongly biased for sampling larger IPSPs.

The BC-to-DTC pair also stresses the potential importance of the relative position of connected cells, because the postsynaptic DTC was located at the edge of the presynaptic axonal field, which may also explain the relatively small number of synapses.
However, we demonstrated previously that pyramidal cells located at the periphery of the presynaptic axonal cloud of BCs can receive a high number $(n=15)$ of unitary synapses (Tamas et al., 1997b). In addition, Kisvarday et al. (1993) found that long-range intercolumnar connections exist between large BCs and other BCs. They observed four to six synapses formed by presynaptic large $\mathrm{BCs}$ on parvalbumin-immunoreactive perikarya; thus, extrapolating from the somatodendritic distribution ratio of synapses between BCs presented in this study, the total number of unitary synapses established by large BCs would be in the range of 10-14 on parvalbumin-positive cells, a value that is close to the mean number of synapses between small BCs presented above. Hence the degree of interconnectivity seems to be governed by the identity of the postsynaptic cell and not by its physical position within the presynaptic axonal field.

The relatively high number of transmitter release sites seems to restrict the number of postsynaptic response failures. Thus, transmission at $\mathrm{BC}$-to-BC connections remains reliable, even if the release probability were relatively low. If we assume binomial release statistics, an average of 12 release sites, and a uniform release probability $(p)$ of $\sim 0.3$ [inhibitory input onto goldfish Mauthner cell (Korn et al., 1982)], the statistical likelihood for all terminals failing to release transmitter would be small $(p \sim 0.01)$. If the same conditions were to apply for $\mathrm{BC}$-to-DBC or DBCto-BC connections with a mean number of unitary synapses in the range of two, the probability of failures would be as high as 0.49 . In view of the absence of a distinct failure peak in the analyzed BC-to-DTC connection, the latter estimate seems to be too high, and the release probability may thus be appreciably higher than that in the case of the Mauthner cell. Hence a high probability of release at cortical GABAergic synapses may serve to ensure a reliable transmission within interneuronal networks.

\section{Subcellular segregation of unitary synapses on GABAergic neurons}

Similar to BC-to-pyramid connections (Somogyi et al., 1983; Kisvarday et al., 1985; Thomson et al., 1996; Tamas et al., 1997b), BCs were found to establish synaptic junctions significantly closer to the soma of postsynaptic GABAergic cells than to that of DBCs. Before the current study, the only unitary interaction between two GABAergic neurons that had been fully analyzed with electron microscopy also demonstrated subcellular domainspecific innervation of a hippocampal bistratified cell by a presynaptic basket cell (Cobb et al., 1997). Moreover, autapses on $\mathrm{BCs}$ are also located more proximal to the soma than are autapses established by DTCs (Tamas et al., 1997c). Such a high degree of domain specificity implies functional differences between synapses formed by perisomatically versus dendritically terminating interneurons in controlling the activity of other GABAergic cells. In pyramidal cells, perisomatic GABAergic synapses may control the generation of APs (Buhl et al., 1995; Miles et al., 1996) and can play a role in phasing neuronal activity (Cobb et al., 1995). Conversely, GABAergic synapses on dendrites can prevent calcium spikes (Traub et al., 1994; Miles et al., 1996) and have been proposed to interact with backpropagating APs (Buzsaki et al., 1996; Tsubokawa and Ross, 1996). An additional explanation for the spatial segregation of GABAergic inputs may be their pairing with excitatory afferents as found in the hippocampus (Gulyas et al., 1993; Halasy and Somogyi, 1993; Vida et al., 1998) and proposed for the neocortex (Kisvarday et al., 1985; Tamas et al., 1997b). 


\section{A role for reciprocally interconnected GABAergic neurons to govern oscillatory network activity}

The high degree of reciprocity and the extent of differential interconnectivity emphasize specificity as well as differentiation in interneuronal networks of the cerebral cortex. In this web, mutually connected interneurons may control spatial and temporal features of inhibition. When linking two GABAergic neurons into a simple serial circuit, this may result in a disinhibitory effect downstream. However, such a simple formula is insufficient to explain the net effect of reciprocally and widely interconnected GABAergic neurons. Recently, a putative functional role for interneuronal interconnections emerged from both experimental and modeling data, showing that, even in the absence of fast glutamatergic neurotransmission, interconnected GABAergic neurons can generate synchronous $40 \mathrm{~Hz}$ network oscillations, provided the degree of synaptic interconnectivity/conductance between cells is sufficiently high (Whittington et al., 1995; Traub et al., 1996; Wang and Buzsaki, 1996). Our data confirm the results of Kisvarday et al. (1993) and clearly favor the web of strongly interconnected BCs to provide an adequate substrate for such synchronous network activity. This notion is experimentally supported by in vivo recordings from the rat hippocampus, demonstrating $\mathrm{BCs}$ to discharge in short, theta-modulated bursts at gamma frequencies (Ylinen et al., 1995). In addition, data presented above show that $\mathrm{BCs}$ generate fast, presumably $\mathrm{GABA}_{\mathrm{A}}$ receptor-mediated synaptic responses in other interneurons, which could be sustained at relatively fast frequencies in the range of and above the gamma frequency band. Such fast IPSPs may then, in turn, entrain a network of tonically excited and mutually connected BCs at gamma frequencies (Buzsaki and Chrobak, 1995; Jefferys et al., 1996). Indeed, during visual stimulation, oscillatory synaptic membrane potential changes have been noted in intracellularly recorded neurons of the cat visual cortex (Jagadeesh et al., 1992), although the spiking activity of putative BCs may not necessarily be periodic (Azouz et al., 1997).

Simulations of the coordinated firing of several neocortical GABAergic neurons providing a perisomatic innervation pattern, namely BCs and axoaxonic cells, indicated that they are well suited to entrain principal cell activity in the gamma frequency range (Lytton and Sejnowski, 1991). However, because axoaxonic cells do not innervate other GABAergic neurons (see Somogyi, 1989), it thus seems that BCs, because of their divergent innervation of both interneurons and principal cells, are uniquely suited to correlate the activity pattern of inhibitory and excitatory cortical neurons. Recordings of BCs and their postsynaptic target neurons in an oscillating network will be required to ascertain their role in the induction and maintenance of cortical network oscillations.

\section{REFERENCES}

Acsady L, Gorcs TJ, Freund TF (1996) Different populations of vasoactive intestinal polypeptide-immunoreactive interneurons are specialized to control pyramidal cells or interneurons in the hippocampus. Neuroscience 73:317-334.

Ahmed B, Anderson JC, Martin KAC, Nelson JC (1997) Map of the synapses onto layer 4 basket cells of the primary visual cortex of the cat. J Comp Neurol 380:230-242.

Andersen P, Eccles JC, Loyning Y (1963) Recurrent inhibition in the hippocampus with identification of the inhibitory cell and its synapses. Nature 198:540-542.

Anderson JC, Douglas RJ, Martin KAC, Nelson JC (1994) Map of the synapses formed with the dendrites of spiny stellate neurons of cat visual cortex. J Comp Neurol 341:25-38.
Avoli M (1986) Inhibitory potentials in neurons of the deep layers of the in vitro neocortical slice. Brain Res 370:165-170.

Azouz R, Gray CM, Nowak LG, McCormick DA (1997) Physiological properties of inhibitory interneurons in cat striate cortex. Cereb Cortex 7:534-545.

Benardo LS (1994) Separate activation of fast and slow inhibitory postsynaptic potentials in rat neocortex in vitro. J Physiol (Lond) 476:203-215.

Buhl EH, Halasy K, Somogyi P (1994) Diverse sources of hippocampal unitary inhibitory postsynaptic potentials and the number of synaptic release sites. Nature 368:823-828.

Buhl EH, Cobb SR, Halasy K, Somogyi P (1995) Properties of unitary IPSPs evoked by anatomically identified basket cells in the rat hippocampus. Eur J Neurosci 7:1989-2004.

Buhl EH, Tamas G, Szilagyi T, Stricker C, Paulsen O, Somogyi P (1997) Effect, number and location of synapses made by single pyramidal cells onto aspiny interneurones of cat visual cortex. J Physiol (Lond) 500:689-713.

Bush P, Sejnowski T (1996) Inhibition synchronizes sparsely connected cortical neurons within and between columns in realistic network models. J Comp Neurosci 3:91-110.

Buzsaki G, Chrobak JJ (1995) Temporal structure in spatially organized neuronal ensembles: a role for interneuronal networks. Curr Opin Neurobiol 5:504-510.

Buzsaki G, Penttonen M, Nadasdy Z, Bragin A (1996) Pattern and inhibition-dependent invasion of pyramidal cell dendrites by fast spikes in the hippocampus in vivo. Proc Natl Acad Sci USA 93:9921-9925.

Cobb SR, Buhl EH, Halasy K, Paulsen O, Somogyi P (1995) Synchronization of neuronal activity in hippocampus by individual GABAergic interneurons. Nature 378:75-78.

Cobb SR, Halasy K, Vida I, Nyiri G, Tamas G, Buhl EH, Somogyi P (1997) Synaptic effects of identified interneurones innervating both interneurones and pyramidal cells in the rat hippocampus. Neuroscience 79:629-648.

Connors BW, Malenka RC, Silva LR (1988) Two inhibitory postsynaptic potentials, and GABAA and GABAB receptor-mediated responses in neocortex of rat and cat. J Physiol (Lond) 406:443-468.

Deuchars J, Thomson AM (1995) Single axon fast inhibitory postsynaptic potentials elicited by a sparsely spiny interneuron in rat neocortex. Neuroscience 65:935-942.

Freund TF, Buzsaki G (1996) Interneurons of the hippocampus. Hippocampus $6: 347-470$.

Freund TF, Meskenaite V (1992) $\gamma$-Aminobutyric acid-containing basal forebrain neurons innervate inhibitory interneurons in the neocortex. Proc Natl Acad Sci USA 89:738-742.

Freund TF, Martin KAC, Smith AD, Somogyi P (1983) Glutamate decarboxylase-immunoreactive terminals of Golgi-impregnated axoaxonic cells and of presumed basket cells in synaptic contact with pyramidal neurons of the cat's visual cortex. J Comp Neurol 221:263-278.

Freund TF, Magloczky Zs, Soltesz I, Somogyi P (1986) Synaptic connections, axonal and dendritic patterns of neurons immunoreactive for cholecystokinin in the visual cortex of the cat. Neuroscience 19:1133-1159.

Gilbert CD, Wiesel TN (1979) Morphology and intracortical projections of functionally characterised neurones in the cat visual cortex. Nature 280:120-125.

Ginsborg BL (1973) Electrical changes in the membrane in junctional transmission. Biochim Biophys Acta 300:289-317.

Gray EG (1959) Axo-somatic and axo-dendritic synapses of the cerebral cortex: an electron microscope study. J Anat 93:420-433.

Gulyas AI, Miles R, Hajos N, Freund TF (1993) Precision and variability in postsynaptic target selection of inhibitory cells in the hippocampal CA3 region. Eur J Neurosci 5:1729-1751.

Gulyas AI, Hajos N, Freund TF (1996) Interneurons containing calretinin are specialized to control other interneurons in the rat hippocampus. J Neurosci 16:3397-3411.

Halasy K, Somogyi P (1993) Subdivisions in the multiple GABAergic innervation of granule cells in the dentate gyrus of the rat hippocampus. Eur J Neurosci 5:411-429.

Han Z-S, Buhl EH, Lorinczi Z, Somogyi P (1993) A high degree of spatial selectivity in the axonal and dendritic domains of physiologically identified local-circuit neurons in the dentate gyrus of the rat hippocampus. Eur J Neurosci 5:395-410.

Jagadeesh B, Gray CM, Ferster D (1992) Visually evoked oscillations of membrane potential in cells of cat visual cortex. Science 257:552-554. 
Jefferys JGR, Traub RD, Whittington MA (1996) Neuronal networks for induced " $40 \mathrm{~Hz}$ " rhythms. Trends Neurosci 19:202-208.

Kisvarday ZF, Martin KAC, Whitteridge D, Somogyi P (1985) Synaptic connections of intracellularly filled clutch cells: a type of small basket cell in the visual cortex of the cat. J Comp Neurol 241:111-137.

Kisvarday ZF, Beaulieu C, Eysel UT (1993) Network of GABAergic large basket cells in cat visual cortex (area 18): implication for lateral disinhibition. J Comp Neurol 327:398-415.

Kisvarday ZF, Kim D-S, Eysel UT, Bonhoeffer T (1994) Relationship between lateral inhibitory connections and the topography of the orientation map in cat visual cortex. Eur J Neurosci 6:1619-1632.

Korn H, Mallet A, Triller A, Faber DS (1982) Transmission at a central inhibitory synapse. II. Quantal description of release, with a physical correlate for binomial n. J Neurophysiol 48:679-707.

Lytton WW, Sejnowski TJ (1991) Simulations of cortical pyramidal neurons synchronized by inhibitory interneurons. J Neurophysiol 66:1059-1079.

Martin KAC, Somogyi P, Whitteridge D (1983) Physiological and morphological properties of identified basket cells in the cat's visual cortex. Exp Brain Res 50:193-200.

Mason A, Nicoll A, Stratford K (1991) Synaptic transmission between individual pyramidal neurons of the rat visual cortex in vitro. J Neurosci 11:72-84.

McCormick DA, Connors BW, Lightall JW, Prince DA (1985) Comparative electrophysiology of pyramidal and sparsely spiny stellate neurons of the neocortex. J Neurophysiol 54:782-806.

Meskenaite V (1997) Calretinin-immunoreactive local circuit neurons in area 17 of the cynomolgus monkey, Macaca fascicularis. J Comp Neurol 379:113-132.

Miles R, Wong RKS (1987) Inhibitory control of local excitatory circuits in the guinea-pig hippocampus. J Physiol (Lond) 388:611-629.

Miles R, Toth K, Gulyas AI, Hajos N, Freund TF (1996) Differences between somatic and dendritic inhibition in the hippocampus. Neuron $16: 815-823$.

Nunzi MG, Gorio A, Milan F, Freund TF, Somogyi P, Smith AD (1985) Cholecystokinin-immunoreactive cells form symmetrical synaptic contacts with pyramidal and non-pyramidal neurons in the hippocampus. J Comp Neurol 237:485-505.

Ramon y Cajal S (1894) La fine structure des centres nerveux. Proc R Soc Lond [Biol] 55:444-468.

Sik A, Penttonen M, Ylinen A, Buzsaki G (1995) Hippocampal CA1 interneurons: an in vivo intracellular labeling study. J Neurosci 15:6651-6665.

Singer W, Gray CM (1995) Visual feature integration and the temporal correlation hypothesis. Annu Rev Neurosci 18:555-586.

Somogyi P (1989) Synaptic organisation of GABAergic neurons and $\mathrm{GABA}_{\mathrm{A}}$ receptors in the lateral geniculate nucleus and visual cortex. In: Proc Retina Res Found Symp, Vol 2, Neural mechanisms of visual perception (Lam DK-T, Gilbert CD, eds), pp 35-62. The Woodlands, TX: Portfolio.
Somogyi P, Cowey A (1981) Combined Golgi and electron microscopic study on the synapses formed by double bouquet cells in the visual cortex of the cat and monkey. J Comp Neurol 195:547-566.

Somogyi P, Soltesz I (1986) Immunogold demonstration of GABA in synaptic terminals of intracellularly recorded, horseradish peroxidasefilled basket cells and clutch cells in the cat's visual cortex. Neuroscience 19:1051-1065.

Somogyi P, Kisvarday ZF, Martin KAC, Whitteridge D (1983) Synaptic connections of morphologically identified and physiologically characterized large basket cells in the striate cortex of cat. Neuroscience 10:261-294.

Szentagothai J, Arbib MA (1974) Conceptual models of neural organization. Neurosci Res Prog Bull 12:305-510.

Tamas G, Buhl EH, Somogyi P (1995) Synaptic responses and effect of physiologically and anatomically identified double bouquet cells in cat visual cortex. Eur J Neurosci [Suppl] 8:76.

Tamas G, Buhl EH, Jones RSG, Somogyi P (1997a) Interactions between distinct GABAergic neuron types eliciting fast IPSPs in cat visual cortex: number and placement of synapses. Soc Neurosci Abstr 23:1265.

Tamas G, Buhl EH, Somogyi P (1997b) Fast IPSPs elicited via multiple synaptic release sites by distinct types of GABAergic neurone in the cat visual cortex. J Physiol (Lond) 500:715-738.

Tamas G, Buhl EH, Somogyi P (1997c) Massive autaptic selfinnervation of GABAergic neurons in cat visual cortex. J Neurosci 17:6352-6364.

Thomson AM, West DC, Hahn J, Deuchars J (1996) Single axon IPSPs elicited in pyramidal cells by three classes of interneurones in slices of rat neocortex. J Physiol (Lond) 496:81-102.

Traub RD, Jefferys JGR, Miles R, Whittington MA, Toth K (1994) A branching dendritic model of a rodent CA3 pyramidal neurone. J Physiol (Lond) 481:79-95.

Traub RD, Whittington MA, Stanford IM, Jefferys JGR (1996) A mechanism for generation of long-range synchronous fast oscillations in the cortex. Nature 383:621-624.

Tsubokawa H, Ross WN (1996) IPSPs modulate spike backpropagation and associated $\left[\mathrm{Ca}^{2+}\right]_{\mathrm{i}}$ changes in the dendrites of hippocampal CA1 pyramidal neurons. J Neurophysiol 76:2896-2906..

Vida I, Halasy K, Szinyei C, Somogyi P, Buhl EH (1998) Unitary IPSPs evoked by interneurons at the stratum-radiatum lacunosum-moleculare border in the CA1 area of the hippocampus in vitro. J Physiol (Lond) 506:755-773.

Wang X-J, Buzsaki G (1996) Gamma oscillation by synaptic inhibition in a hippocampal interneuronal network model. J Neurosci 16:6402-6413.

Whittington MA, Traub RD, Jefferys JGR (1995) Synchronized oscillations in interneuron networks driven by metabotropic glutamate receptor activation. Nature 373:612-615.

Ylinen A, Soltesz I, Bragin A, Penttonen M, Sik A, Buzsaki G (1995) Intracellular correlates of hippocampal theta rhythm in identified pyramidal cells, granule cells, and basket cells. Hippocampus 5:78-90. 